\title{
Differing effects of eelgrass Zostera marina on recruitment and growth of associated blue mussels Mytilus edulis
}

\author{
Thorsten B. H. Reusch* \\ Institut für Meereskunde, Abteilung Meeresbotanik, Düsternbrooker Weg 20, D-24105 Kiel, Germany \\ and \\ Department of Marine Biology, University of Groningen, PO Box 14, 9750 AA Haren, The Netherlands**
}

\begin{abstract}
I studied the effects of habitat structure, provided by an eelgrass Zostera marina canopy, on shell growth rate and recruitment of co-occurring blue mussels Mytilus edulis in the Western Baltic Sea. $M$ edulis in clumps consisting of 10 and 30 individuals were tagged and placed in unvegetated areas and in the centers of small, medium and large eelgrass patches $(0.8$ to $1.6 \mathrm{~m}, 1.6$ to $3.2 \mathrm{~m}$, and $>4 \mathrm{~m}$ across, respectively). Inside eelgrass, $M$. edulis growth was approximately one-third of that in adjacent unvegetated areas, regardless of vegetated patch size and mussel clump size. In contrast, mussel recruitment, assessed as abundanre of 1 to $5 \mathrm{~mm}$ long juveniles, was enhanced by the presence of eelgrass, and was highest in medium-size eelgrass patches where juveniles were $\sim 3 \times$ as dense as in clumps on the sand flat. Populations of animals associated with seagrasses can thus be enhanced and depressed simultaneously by the plant canopy, depending on the response variable. Moreover, the snatial sit uciure of the vegetation, in this case eelgrass patch diameter, may be important for one response variable (recruitment) but irrelevant for another (shell growth).
\end{abstract}

KEY WORDS: Biotic interaction - Habitat structure - Zostera marina - Mytilus edulis - Spatial scale . Patchiness - Recruitment - Growth

\section{INTRODUCTION}

Habitat structure, the physical arrangement of objects in space (Bell et al. 1991), has a major influence on the distribution of species. On marine soft bottoms, the leaf canopies of seagrasses provide habitat for many epibenthic animal species in an otherwise unstructured environment (Orth 1992). Gregarious suspension feeders such as blue mussels Mytilus edulis $\mathrm{L}$. and M. trossulus Gould commonly co-exist with eelgrass Zostera marina L. in coastal areas of the northern temperate zone such as the Baltic Sea (Bostrom \& Bonsdorff 1997), the Canadian east coast (Robertson \& Mann 1984, author's pers. obs.), and the North Sea (Ruth 1991). Some positive feedback between populations of $M$. edulis and $Z$. marina has already been identified in the Baltic Sea. Mussels enhanced eelgrass

\footnotetext{
·E-mail: t.reusch@biol.rug.nl

- Present address
}

growth by means of fertilization if kept in check by mussel predators (Reusch et al. 1994). In the same study, there was no interference effect of mussels on eelgrass, although individual leaf shoots were damaged by $M$. edulis. Mussel abundance was enhanced by eelgrass because the canopy acted as a collector for drifting mussel clumps and also reduced the risk for dislodgement of established mussel beds by waves during storms (Reusch \& Chapman 1995). In addition to the observations from the Baltic, there are reports of enhancement of mussel recruitment through the presence of an eelgrass canopy from other northern temperate shores (Newell et al. 1991, Short et al. 1991).

Here, I present the results of an experiment assessing the effects of eelgrass on recruitment rates and individual growth of blue mussels Mytilus edulis. Previous studies have demonstrated the importance of the small- and medium-scale spatial structure of seagrass meadows for growth and survival of associated bivalves (e.g. Irlandi \& Peterson 1991, Irlandi 1994, 
1996). Therefore, in addition to the effects of eelgrass presence/absence, I also assessed the influence of spatial scale, i.e. of eelgrass patch size, on $M$. edulis because many Zostera marina beds in the western Baltic Sea display a patchy structure.

\section{MATERIALS AND METHODS}

I carried out all observations and experiments at Maasholm, Kiel Bight, Germany, Baltic Sea $\left(54^{\circ} 41^{\prime} N_{1}\right.$ $10^{\circ} 00^{\prime} \mathrm{E}$ ), by means of snorkeling or scuba. Maasholm is situated $3 \mathrm{~km}$ from the mouth of the outer Schlei estuary, a shallow (1 to $6 \mathrm{~m}$ depth), soft-bottom embayment which is dominated by adjacent Kiel Bight water masses. This dominance is reflected in the salinities, which are similar to Kiel Bight proper and range from 13 to $15 \mathrm{~g} \mathrm{~kg}^{-1}$ during the summer months (Schramm et al. 1996). Water temperatures ranged from 15 to $24^{\circ} \mathrm{C}$ during the study period (H. K. Lotze \& B. Worm unpubl. data).

I selected Maasholm for the experiment because both blue mussels Mytilus edulis L. and eelgrass Zostera marina L. are abundant on the sandy substratum of this site (author's unpubl. data). Moreover, eelgrass patches of a large size range were present $(0.5$ to $8 \mathrm{~m}$ in diameter) in the shallow subtidal zone ( 1 to $2 \mathrm{~m})$, allowing a test of eelgrass patch size on individual growth rates and recruitment of the mussel population. The total vegetation cover of the eelgrass bed in a mapped area of $20 \times 40 \mathrm{~m}$ was $28 \%$. Thus, vegetated patches were sufficiently isolated from one another by at least $1.5 \mathrm{~m}$ of sand flat, minimizing the effects of neighboring vegetation on any patch selected as an experimental unit. At Maasholm, $M$. edulis mainly occur as clumps consisting of 5 to 100 individuals attached to one another by means of their byssus. Usually abundant mussel predators such as green crabs Carcinus maenas and seastars Asterias rubens are rare at the site and were absent during the study period (author's unpubl. obs.), obviating the need to consider habitat-specific mortality rates through predation in the experimental design.

In order to address the effects of eelgrass presence and patch size on mussel shell growth and recruitment rates, I constructed mussel clumps using adult individuals collected at the site. Immediately after collection, I separated the adult mussels and removed all juveniles (<10 mm shell length). Mussels (standard length $\pm \mathrm{SE}=$ $28.09 \pm 0.3 \mathrm{~mm}, \mathrm{~N}=300$ ) were then tagged for $24 \mathrm{~h}$ in a solution of calcein (Sigma chemical No. C0875) in aerated ambient seawater $\left(100 \mathrm{mg} \mathrm{l}^{-1}, \mathrm{pH}=8.0\right)$. The tagging efficiency in Mytilus edulis, determined in a subsample of 50 individuals, was $80 \%$. Because waveand current-induced drift of mussel clumps is common in soft-bottom areas such as the western Baltic (Reusch
\& Chapman 1995), I let the mussels attach to an artificial solid substratum to facilitate the recovery of experimental individuals. The mussels were first placed onto one large $(1 \times 1 \mathrm{~m})$ sheet of polyethylene mesh fabric (mesh size $10 \times 10 \mathrm{~mm}$, gauge size $2 \mathrm{~mm}$ ) which was fixed on the sand flat in the field. I allowed the mussels $3 \mathrm{~d}$ to attach to the fabric by means of their byssi. The mesh was then cut to obtain mussel clumps consisting of the desired number of individuals. The polyethylene substratum had no effect on mussel survival and growth in a previous study (Reusch \& Chapman 1997).

Four small (10 individuals each) and 4 large (30 individuals each) mussel clumps were placed in the center of each of the following 4 habitats: (1) unvegetated sand flat; (2) small eelgrass patch $(0.8$ to $1.6 \mathrm{~m}$ in diameter); (3) medium eelgrass patch ( 1.6 to $3.2 \mathrm{~m}$ in diameter); and (4) large eelgrass patch (>4 $\mathrm{m}$ in diameter). The eelgrass patch diameter refers to the length of continuous vegetation parallel to the shore. Wind-driven currents at the site run only alongshore (author's unpubl. obs.) and I assumed that the alteration of these current patterns by the vegetation would be the most likely effect influencing mussels. I selected the locations for the mussel clump transplantations haphazardly within an area of $150 \mathrm{~m}$ (parallel to shore) $\times 20 \mathrm{~m}$ (perpendicular to shore). Each mussel clump was placed in a different eelgrass patch or sand flat and, thus, represented an independent observation. The clumps attached to the meshes were fixed in the selected experimental locations with $20 \mathrm{~cm}$ long stakes. Mesh and stakes were completely buried in the sediment. To avoid effects of nearby vegetated patches, I ensured that each eelgrass patch was at least $2 \mathrm{~m}$ from others. In the sand flat treatments, all mussel clumps were more than $3 \mathrm{~m}$ away from any vegetation.

Two weeks after the initiation of the experiment on 24 June 1997 I counted the eelgrass shoot density (in $50 \times 50 \mathrm{~cm}$ quadrats) and the shoot height ( 3 plants patch $^{-1}$ ) in each of the 24 experimental eelgrass patches. Mean \pm SE Zostera marina shoot height $(62 \pm$ $1.8 \mathrm{~cm}$ ) was independent of eelgrass patch size (ANOVA, $p=0.47$ ). There was a tendency for shoot density to increase with patch size (ANOVA, $p=0.09$ ). Mean \pm SE shoot density per $0.25 \mathrm{~m}^{2}$ pooled over all treatments was $32 \pm 1.9(\mathrm{~N}=24)$.

The experiment ran until 23 August 1997 (60 d). After retrieval, I counted juvenile mussels (shell length 1 to $5 \mathrm{~mm}$ ) in each experimental mussel clump as a measure of recruitment. Since mussel recovery varied considerably among clumps ( 3 to 42 mussels recovered) and recruitment densities were a strong linear function of the number of adult mussels remaining in a given clump (linear regression, $p=0.02$ ), I standardized the number of juvenile mussels by dividing by the number of live adult mussels. 
After bleaching all adult Mytilus edulis in $4 \%$ sodium hypochlorite solution (household bleach), shell growth increments were determined under UV-epifluorescence at $16 \times$ magnification. I calculated specific shell growth rates over the entire $60 \mathrm{~d}$ period as $\ln$ (final length) - $\ln$ (initial length). Specific growth rates were not corrected for initial size differences (Kaufmann 1981) because all tested growth models (von Bertalanffy, power, Gompertz) yielded only a poor fit (coefficient of determination $\mathrm{R}^{2} \leq 0.11$ ). In addition, the differences in initial mussel sizes among plots and treatments were small and not significant.

\section{RESULTS}

After the $60 \mathrm{~d}$ experimental exposure, I recovered on average $( \pm \mathrm{SE}) 8.9 \pm 0.9$ live mussels from the small and $22.7 \pm 1.5$ from the large mussel clumps. The number of recovered individuals was independent of eelgrass presence and patch size (1-way ANOVA, $F_{3,26}=1.103$, $\mathrm{p}=0.37$ ). In a total of 290 mussels ( $=59 \%$ of recovered individuals) a clear calcein growth ring was incorporated into the shell and allowed measurement of growth. The percentage of tagged individuals in the patches was, thus, lower than the initial tagging rate of individuals $(80 \%)$, indicating that non-tagged adult mussels immigrated to the experimental clumps. The experinentai design became unbalanced because 1 small mussel clump designated as a large eelgrass patch treatment was erroneously assigned to the sand flat (thus $N=9$ for sand flat and $N=7$ for eelgrass) and 1 medium eelgrass patch treatment could not be relocated (thus $\mathrm{N}=7$ )

\section{Effects of eelgrass on mussel growth}

Within the center of eelgrass patches, mussel growth was approximately one-third of that in adjacent unvegetated areas (Fig. 1). During the $60 \mathrm{~d}$ exposure, an average individual of $28 \mathrm{~mm}$ shell length grew

Table 1. Analysis of the effects of eelgrass Zostera marina presence and patch size on the specific growth rates [ln (final shell length) - In (initial shell length)] of Mytilus edulis through a 2 -way $(4 \times 2)$ ANOVA. For each experimental mussel clump, only 1 value for mean growth rate was obtained. Data meet the assumption of variance homogeneity (Cochran's test)

\begin{tabular}{|lrrrr|}
\hline Source of variance & df & MS $\times 10^{3}$ & $F$ & $p$ \\
\hline Eelgrass presence/patch size & 3 & 302 & 18.6 & $<0.0001$ \\
Mussel density & 1 & 2 & 0.15 & 0.70 \\
Eelgrass $\times$ Density & 3 & 12 & 0.75 & 0.53 \\
Residual & 23 & 16 & & \\
\hline
\end{tabular}
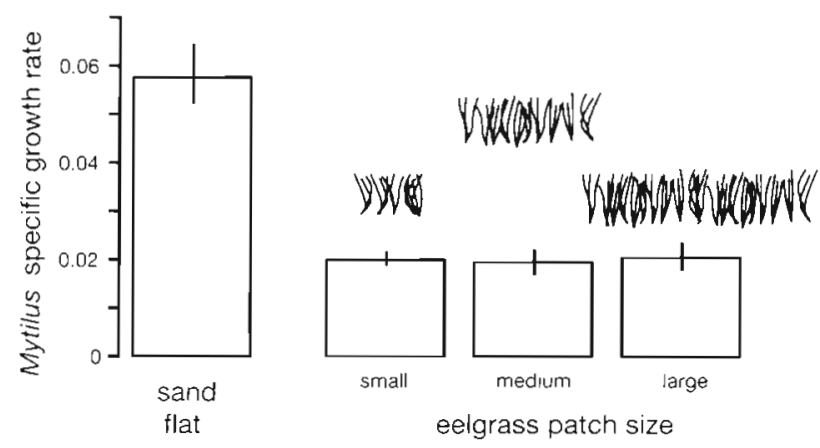

Fig. 1 Mytilus edulis. Mean specific shell growth rates $\pm \mathrm{SE}$ on unvegetated sand flat and in eelgrass Zostera marina patches of 3 different diameters. Data were pooled over $M$. edulis density because this factor was not significant (Table 1)

$1.61 \mathrm{~mm}$ in length on the sand flat and only $0.56 \mathrm{~mm}$ inside the eelgrass. The marked reduction in growth rates was independent of the size of the vegetated patches and almost equal in small, medium and large eelgrass patches (Fig. 1). There was no interaction of eelgrass patch size with adult mussel density ( 10 or 30 individuals per clump). The main factor 'mussel density' was also not significant (Table 1).

\section{Effects of eelgrass on mussel recruitment}

Most of the mussel recruits found on their adult conspecifics were small ( $<3 \mathrm{~mm}$ shell length) and, thus, most likely represented primary settlers. Mussel recruitment intensity displayed a dome-shaped function of patch size (Fig. 2). Recruitment rates, standardized to the number of adult mussels in each clump, were highest in medium-sized eelgrass patches $(1.6$ to $3.2 \mathrm{~m}$ in diameter), where they were $2.8 \times$ higher than
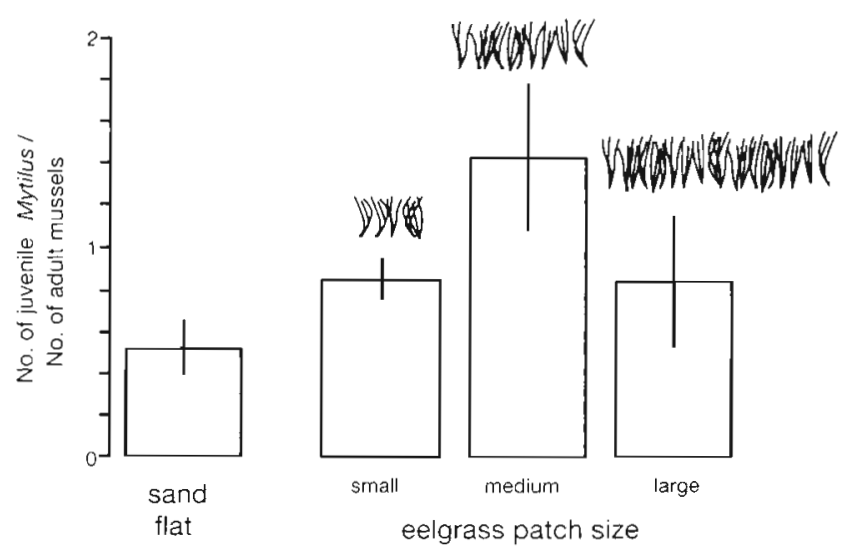

Fig. 2. Mytilus edulis. Mean number of juveniles (shell length 1 to $5 \mathrm{~mm}$ ) per adult in each clump \pm SE as a function of eelgrass Zostera marina presence and patch diameter. The overall ANOVA model is marginally significant (see text) 
in the mussel clumps on the sand flat. Recruitment densities declined with further increase in eelgrass patch size (diameter $>4 \mathrm{~m}$ ). The overall ANOVA was only marginally significant (square root transformed counts, 1 -way ANOVA, $\mathrm{MS}_{\text {error }}=0.113, F_{3,27}=2.8, \mathrm{p}=$ 0.059 ) because the error variances for juvenile Mytilus edulis densities within treatments were high. In a planned contrast, comparing all vegetated habitats with the sand flat, pooled recruitment rates were approximately double inside eelgrass compared to the sand flat treatment, a difference which was significant (square root transformed counts, $\mathrm{MS}_{\text {error }}=0.49, F_{1,29}=$ 4.37, $\mathrm{p}=0.046)$.

\section{DISCUSSION}

Two population parameters in soft-bottom inhabiting blue mussels Mytilus edulis, individual growth and recruitment rates, were markedly different among eelgrass Zostera marina patches and adjacent sand flats. Whereas recruitment rates approximately doubled inside the vegetation, mussel growth rates were reduced by almost two-thirds. The effect of spatial scale, i.e. eelgrass patch size, also varied between the 2 response variables. The diameter of vegetated patches probably influenced recruitment rates but did not affect mussel growth rates.

Although the increase in mussel recruitment intensity with the presence of the aquatic vegetation was only marginally significant, the present findings are consistent with those from eelgrass beds in the Northwest Atlantic (Newell et al. 1991, Short et al. 1991) and with data collected in 1992/1993 at another site in the Western Baltic Sea (Reusch 1994). In that latter study, on 4 of 5 quarterly dates, I found juvenile mussel abundances to be 2 to $4 \times$ higher in mussel beds occurring together with an eelgrass canopy than in pure mussel beds and clumps. I did not differentiate eelgrass patch size which varied between 1 and $4 \mathrm{~m}$, thus corresponding to the small and medium Zostera marina patches of the present study which showed an enhancement of recruitment. Therefore, it is likely that small to medium patches have a positive effect on the number of mussels settling on adult Mytilus edulis patches. Whether this enhancement is compensated by a settlement shadow (Orth 1992) once the patch size increases beyond $4 \mathrm{~m}$ remains to be verified.

This study was not devoted to identification of potential mechanisms through which a macrophyte canopy affects mussel individual growth and recruitment. Rather, as a starting point, I intended to assess the nature of the effects of eelgrass on mussels as a function of eelgrass presence and patch size. It is likely that the alteration of water movement inside the canopy is responsible for the effects observed. The upright blades of seagrasses represent large roughness elements (Nowell \& Jumars 1984) which markedly alter the hydrodynamic regime inside the canopy through momentum extraction (Gambi et al. 1990). Consequently, on a mechanistic basis, the responses of bivalves to aquatic vegetation have been successfully related to altered current regimes and food supply in some studies (e.g. for shell growth: Irlandi \& Peterson 1991, T. B. H. Reusch \& S. L. Williams unpubl,; for recruitment: Eckman 1989)

Reduced mussel growth rates in the present study are most likely due to a reduced food supply as water slows down entering the canopy (Reusch \& Williams unpubl.). Mechanistic explanations why mussel recruitment was enhanced through eelgrass were beyond the scope of the study. Possibly, the turbulence induced by the upright eelgrass leaves increases the chance for settlers to come into contact with the bottom (Eckman 1990). In addition, inside the canopy, Mytilus edulis plantigrades can settle on the much larger surface area of the eelgrass leaves (e.g. Short et al. 1991). Juvenile $M$. edulis attach to the blades for a short time period only to move to the bottom once the Zostera marina leaf is shed (every $30 \mathrm{~d}_{i}$ author's unpubl. data). thereby increasing the recruitment rates to adult $M$ edulis clumps or beds.

The literature abounds with examples of increased faunal abundance and diversity in seagrass meadows compared to nearby unvegetated areas (overview in Orth 1992). Faunal densities are often enhanced because inside the vegetation sediment disturbance is reduced (e.g. Orth 1977), predation rates are lower (e.g. Summerson \& Peterson 1984), and faunal recruitment rates are higher (e.g. Eckman 1989). Negative effects have been reported less frequently (but see Kerswill 1949). I am not aware of any study demonstrating that the presence of macrophytes simultaneously enhances and depresses populations of associated fauna depending on the response variable. With respect to different microhabitats within the canopy of seagrasses only, Ambrose \& Irlandi (1992) identified a trade-off between predation risk and growth for juvenile Argopecten irradians living attached to eelgrass blades. The predation rates on the bivalves decreased with proximity to the sediment surface, whereas their individual growth rates increased along the same gradient.

Given the 2 opposite effects of eelgrass on Mytilus edulis identified in this study, it is not possible to decide whether the overall effect of eelgrass on associated mussel populations is positive, neutral, or negative. For this purpose, it will be necessary to model $M$. edulis population growth with a stage-structured model over an entire year, incorporating all relevant 
transition probabilities between size stages. In addition, positive effects of the vegetation which captures drifting mussel clumps and the reduced risk of dislodgement by waves for clumps inside the eelgrass should be incorporated (Reusch \& Chapman 1995).

The growth of clams Mercenaria mercenaria on the North American East Coast is often higher inside seagrass canopies than outside (e.g. Peterson et al. 1984, Irlandi \& Peterson 1991, Irlandi 1996). Higher growth rates of $M$. mercenaria have been successfully related to increased food availability inside the vegetation (Judge et al. 1993). In contrast, this study, and parallel experiments in southern California, USA, on the effects of eelgrass on populations of another gregarious mussel, Musculista senhousia (Reusch \& Williams unpubl.) revealed marked reductions in bivalve growth inside eelgrass, which were paralleled by lower food availability and water movement inside the canopy. These conflicting results suggest that generalizations on seagrass-bivalve interactions are not possible given our present knowledge. More experiments are needed to identify the critical properties of (1) the structure and species composition of the aquatic vegetation, (2) the taxonomic affiliation of the bivalve species, and (3) the hydrodynamic regime at the site (e.g. tidal vs wind-driven currents) to predict vegetation effects on bivalve populations.

Acknowledgements. i hiank A. C. Bockelmann tor field assistance, A.R.O. Chapman for improving the language, and B. Worm, A. Albrecht, and 3 anonymous reviewers for comments on the manuscript. The experiments were carried out near the field station Maasholm of the Institute of Marine Science, Kiel.

\section{LITERATURE CITED}

Ambrose WG Ji, Irlandi EA. (1992) Height of attachment on seagrass leads to trade off between growth and survival in the bay scallop Argopecten irradians. Mar Ecol Prog Ser 90:45-51

Bell SS, McCoy ED, Mushinsky HR (1991) Habitat structure. Chapman and Hall, London

Boström C, Bonsdorff E (1997) Community structure and spatial variation of benthic invertebrates associated with Zostera marina $\mathrm{L}$. beds in the northern Baltic Sea. J Sea Res 37:153-166

Eckman JE (1989) The role of hydrodynamics in recruitment, growth, and survival of Argopecten irradians (Say) and Anomia simplex (D'Orbigny) within eelgrass meadows. J Exp Mar Biol Ecol 106:165-191

Eckman JE (1990) A model of passive settlement by planktonic larvae onto bottoms of differing roughness. Limnol Oceanogr 35:887-901

Gambi MC, Nowell ARM, Jumars PA (1990) Flume observations on flow dynamics in Zostera marina (eelgrass) beds. Mar Ecol Prog Ser 61:159-169

Irlandi EA (1994) Large- and small-scale effects of habitat structure on rates of predation: how percent coverage of seagrass affects rates of predation and siphon nipping on an infaunal bivalve. Oecologia 98:176-183
Irlandi EA (1996) The effects of seagrass patch size and energy regime on growth of a suspension-feeding bivalve. J Mar Res 54:161-185

Irlandi EA, Peterson CH (1991) Modification of animal habitat by large plants: mechanisms by which seagrasses influence clam growth. Oecologia 87:307-318

Judge ML, Coen LD, Heck KL.Jr (1993) Does Mercenaria mercenaria encounter elevated food levels in seagrass beds? Results from a novel technique to collect suspended food resources. Mar Ecol Prog Ser 92:141-150

Kaufmann KW (1981) Fitting and using growth curves. Oecologia 49:293-299

Kerswill CJ (1949) Effects of water motion on the growth of quahaugs and oysters. J Fish Res Bd Can 7:545-551

Newell CR, Hidu H, McAlice BJ, Podniesinski G, Short F, Kindblom L (1991) Recruitment and commercial seed procurement of the blue mussel Mytilus edulis in Maine. J World Aquacult Soc 22:134-152

Nowell ARM, Jumars PA (1984) Flow environments of aquatic benthos. Annu Rev Ecol Syst 15:303-328

Orth RJ (1977) The importance of sediment stability in seagrass communities. In: Coull BC (ed) Ecology of marine benthos. University of South Carolina Press, Columbia, p 281-300

Orth RJ (1992) A perspective on plant-animal interactions in seagrasses: physical and biological determinants influencing plant and animal abundance. In: John DM, Hawkins $\mathrm{SJ}$, Price JH (eds) Plant-animal interactions in the marine benthos. Clarendon Press, Oxford, p 147-164

Peterson CH, Summerson HC, Duncan PB (1984) The influence of seagrass cover on population structure and individual growth rate of a suspension-feeding bivalve, Mercenaria mercenaria. J Mar Res 42:123-138

Reusch TBH (1994) Factors structuring the Zostera- and Mytilus- community in the Western Baltic: an experimental approach. Ber Inst Meereskunde Kiel 254:1-164

Reusch TBH, Chapman ARO (1995) Storm effects on eelgrass (Zostera marina L.) and blue mussel (Mytilus edulis L.) beds. J Exp Mar Biol Ecol 192:257-271

Reusch TBH, Chapman ARO (1997) Persistence and space occupation of subtidal blue mussel patches. Ecol Monogr $67: 65-87$

Reusch TBH, Chapman ARO, Gröger JP (1994) Blue mussels (Mytilus edulis) do not interfere with eelgrass (Zostera marina) but fertilize shoot growth through biodeposition. Mar Ecol Prog Ser 108:265-282

Robertson AI, Mann KH (1984) Disturbance by ice and lifehistory adaptations of the seagrass Zostera marina. Mar Biol 80:131-141

Ruth M (1991) Miesmuschelfischerei im schleswig-holsteinischen Wattenmeer Ein Beispiel für die Problematik einer Fischerei im Nationalpark. In: Dethlefsen V (ed) Probleme der Muschelfischerei im Wattenmeer. Schriftenreihe der Schutzgemeinschaft Deutsche Nordseeküste e.V., Wilhelmshaven, p 26-46

Schramm W, Lotze H, Schories D (1996) Eutrophication and macroalgal blooms in inshore waters of the German Baltic coast: the Schlei Fjord. In: Rijstenbil JW, Kamermans P, Nienhuis PH (eds) EUMAC Synthesis Report. EU-commission contract no. EV5V-CT93-0290, p 17-73

Short F, Hidu H, Hoven H, Kindblum L, Newell K, Verny K, Mathieson A (1991) The role of eelgrass (Zostera marina) in the recruitment of the blue mussel (Mytilus edulis) in Maine. J Shellfish Res 10:300-301 (abstract only)

Summerson HC, Peterson CH (1984) Role of predation in organizing benthic communities of a temperate-zone seagrass bed. Mar Ecol Prog Ser 15:63-77 